\title{
28. Introduction
}

\section{B. Friis}

\section{POLICY RELEVANCE AND INTERNATIONAL FRAMEWORK}

Waste represents a loss of resources, and the spread of emissions from treatment and disposal of waste to air, soil and water over a period. In addition, there is a risk of unintended emission of undesirable substances.

Waste is an environmental problem of growing concern. The principal question is 'how can we improve our welfare without continuously increasing the amounts of waste and the related environmental problems?'. Several policies have addressed this question, for example, the UN and the EU have adopted a well-known priority ranking for dealing with waste (waste minimization, recycling, treatment with energy recovery, sanitary landfilling). ${ }^{1}$

The Basel Convention on hazardous waste has been adopted by many countries, including the EU, ${ }^{2}$ and more recently, Agenda $21^{3}$ has highlighted waste as one of the topics to address.

At EU level, the Fifth Environmental Action Programme ${ }^{4}$ has formulated a strategy to stabilize waste production at the 1985 level by the year 2000 .

\section{RESULTS OF SECOND-ROUND QUESTIONNAIRE}

A second questionnaire submitted to waste experts asked them to rank the 30 indicators condensed from the first questionnaire ${ }^{5}$ on the basis of three quality criteria defined as 'policy relevance', 'analytical soundness' and 'responsiveness'. Figure 28.1 shows the overall rankings for these three questions. The core ranking of the indicators is also presented, expressed as a percentage of experts who included the indicator in their top-five list of essential indicators.

It should be noted that there is some disagreement between the core rankings and the quality question rankings. The top two core-ranked indicators are 'waste landfilled' and 'waste incinerated', which relate to waste treatment, whereas the top two indicators for all three quality questions are 'hazardous waste' and 'municipal waste', which relate to waste types. There is also less 
Pressure indicators for waste:

'quality' questions Q1-3, core-ranked

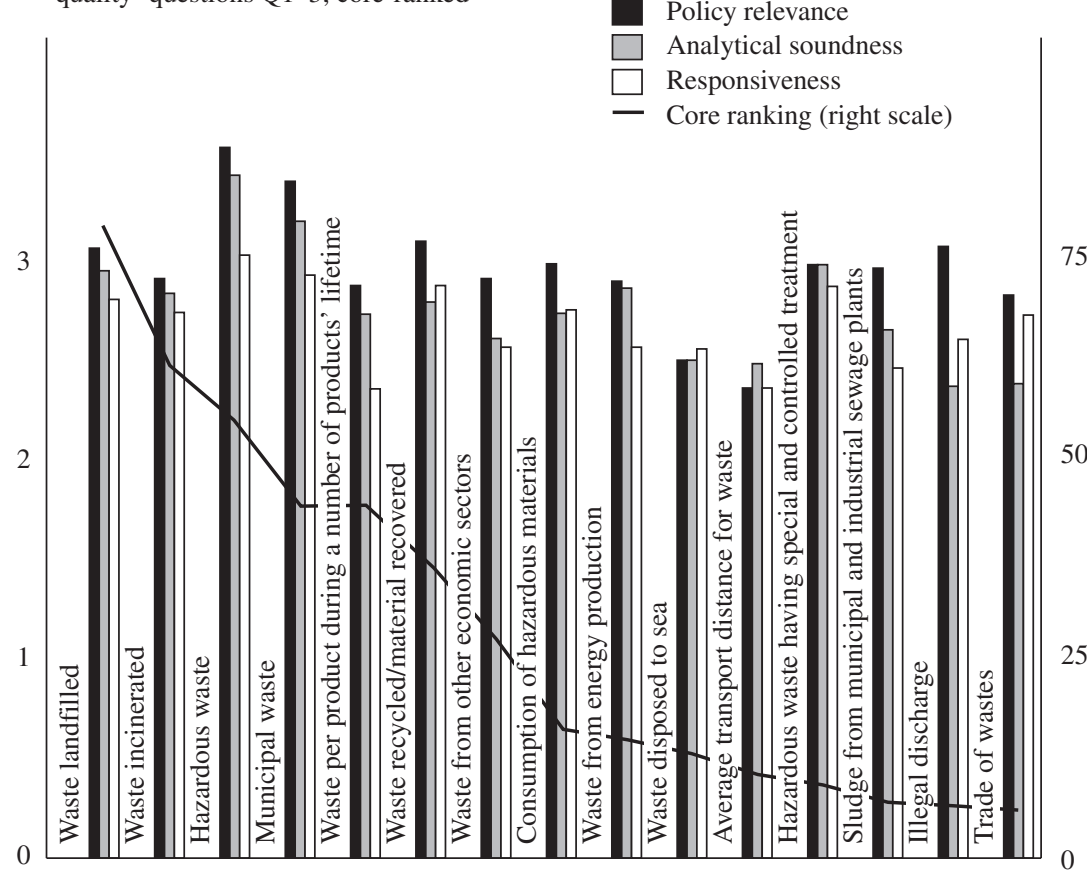

Ranking $(1=$ very low, 4 = very high $)$ :

- Policy relevance

Analytical soundness

Responsiveness

Core ranking (right scale)

Figure 28.1 Results of second-round questionnaire for the Waste policy field

agreement compared to some other policy fields between core rankings and quality question ranking for indicators further down the rankings.

The highest core-ranked indicator representing a more broad life-cycle approach is 'waste per product during a number of products' entire lifetime', which is fifth, although it is ranked lower for the quality questions. Indicators on various emissions from waste treatment are not represented.

\section{DELIMITATION OF THE WASTE POLICY FIELD}

'Waste' is a word used in different ways in various countries. It is defined in Directive 75/442/EEC as 'any substance or object in the categories set out in Annex I which the holder discards, or intends or is required to discard'.

The policy field of Waste comprises hazardous and non-hazardous solid waste from households, municipalities, industry, energy production, hospi- 
tals, construction works and other societal activities. Exported waste should also be included since it might exert a pressure on the environment in the receiving country.

In some countries, certain wastes, such as nuclear waste, military waste, and manure, are covered by different legislation and are recorded separately from other types of waste. ${ }^{6}$

\section{Links}

For the Waste policy field the most important links with other policy fields are the following:

\section{Dispersion of Toxic Substances}

Waste is one way of dispersing toxins. The Dispersion of Toxic Substances policy field concentrates on the total production/consumption of various toxic substances, while the policy area of Waste includes the amounts of hazardous solid waste and their treatment. Contaminated soil from past activities is a state indicator and at present not included in the list of environmental pressure indicators. A pressure indicator measuring the annual increase in contaminated soil due to waste treatment is proposed for the Waste policy field.

\section{Water Pollution and Water Resources}

Waste can be a threat to water due to illegal discharge, leachate from landfills, and dumping into the sea. Sludge is in some Member States regarded as waste and counted together with other waste types. In other countries it is regarded as a potential problem for water resources. It can also be seen as a resource for agriculture. One of the proposed indicators for waste is sludge from sewage plants.

\section{Resource Depletion}

Waste can be regarded as a potential or lost resource. Energy consumption in production and waste treatment is included in the Resource Depletion policy field; however, recycling of waste is dealt with in the Waste policy field. Sludge and manure might be considered as a resource, a potential pollutant for water or even a waste. It is proposed that manure be dealt with under Resource Depletion.

\section{Air Pollution}

Treatment of waste (for example, incineration) can cause air pollution, depending on the waste type and the technology applied. However, treatment of waste is included in the Waste policy field; for example, one of the proposed 
indicators is 'Dioxins emissions from waste incineration'. Air pollution indicators concentrate on the total emissions of various pollutants.

\section{Ozone Depletion}

Decomposition of waste at landfills generates methane, which contributes to the depletion of the ozone layer. The methane can be converted to $\mathrm{CO}_{2}$ if the gas is incinerated, thereby reducing the effect on the ozone layer. An indication of such contributions to ozone depletion from the Waste policy field can be given by registering which types of waste are landfilled at which kind of landfill (for example, with/without incineration of landfill gas).

\section{Urban Environmental Problems}

Municipal waste is one of the topics dealt within the Urban Environmental Problems policy field. The Waste policy field includes all types of waste viewed on a national basis.

\section{CONTRIBUTIONS IN THE WASTE POLICY FIELD}

As a contribution to the development of indicators in the Waste policy field, three experts were asked to write a chapter. Three different writers from three different EU Member States were found. Dr Donald Huisingh is involved with the new trends of cleaner production and sustainability, Peter Gössele specializes in waste management, planning and statistics, and Professor Franco Cecchi is concerned with research on waste treatment and monitoring.

Donald Huisingh's contribution (Chapter 29) poses questions about environmental pressure indicators and how they can be developed and used in combination with other tools in order to facilitate progress of societies toward sustainability. Huisingh warns that the pressure indicators standing alone are simplifications, focusing on end-of-pipe solutions and compartmentalization of environmental problems. He reminds us that environmental problems are interconnected (one moment we have solid waste and the next we have an emission to air or water) and encourages a further development of pressure indicators within the new paradigm of waste prevention and cleaner production. In addition, he suggests that closer links between environmental pressure indicators, and governmental policies and instruments be established.

The chapter by Jordan and Gössele (Chapter 30) describes the historical development of waste production. Efficient incentives are needed to reduce quantities of waste and the levels of hazardous waste, and to ensure environmentally safe treatment. The solutions are not simple. For example, the authors question the idea that recycling is always an environmental advan- 
tage. Although - and because - the situation is complicated, Gössele and Jordan welcome the Eurostat development of a system of indicators to provide an overview for non-expert politicians, administrators and the public. The authors recommend that the problems of potential misinterpretation of data be avoided by professional use and regular reassessments

The chapter by Professor Cecchi and Dr Pavan (Chapter 31) explains that waste must be considered as an integral part of production. The environmental problems related to waste can be expressed by the physical law on entropy, and the chapter sets out how this approach can guide industry and the public towards a better utilization of resources by using cleaner technology instead of 'downstream' technologies. Cecchi and Pavan discuss the present environmental problems related to waste and suggest that 'technical obstacles to economic exchange' be removed in order to improve the market for recyclables, to avoid 'over-production of waste' and in order to avoid decisions on waste management being taken on a short-term economic basis only.

The chapter lists a range of definite actions to be taken within waste management: for example, how to improve sanitary landfills and how to treat biological waste, together with sewage sludge.

Cecchi and Pavan expect that an environmental pressure index for waste will contribute to an improved communication with the public, and among administrators and politicians, and hope that this and other actions will result in an increased rationality in defining waste policy, in production decisions and in public opinion.

\section{NOTES}

1. Council Directive on Waste (91/156/EEC) (the 'Framework Directive').

2. Basel Convention on the Control of Transboundary Movements of Hazardous Waste and their Disposal, SBC No. 94/008.

3. Second UN Conference on Environment and Development in Rio de Janeiro (1992).

4. See terminology in Annex IV.

5. First questionnaire: December 1995; second questionnaire: October 1996. See Editors' introduction.

6. Directive 91/156/EEC on waste excludes from Article 2 radioactive waste, mining waste, some agricultural waste and explosives if they are already covered by other legislation. 